Çeşm-i Cihan:

Tarih Kültür ve Sanat Araștırmaları E - Dergisi ISSN: 2149-5866 Cilt:8, Sayı:1, s. 82-91, Yaz 2021

Araștırma-İnceleme

DOİ: $10.30804 /$ cesmicihan.888270 BARTIN - TÜRKIYE
Bartın Üniversitesi

Bartın ve Yöresi

Tarih - Kültür Araştırmaları

Uygulama ve Araştırma

Merkezi

(BAYTAM)

\title{
TÜRK HALK KÜLTÜRÜNDE VE EDEBIYYATINDA YEDİ SAYISI
}

\section{Lazzat TOREBEKKYZY*}

Öz: Mitolojik zamanlarda insanlar kendisini, doğa olaylarını tanımaya çalışmıştır. Sonra da kendilerini bu tabiatın bir parçası olarak düşünmeye başlamıştır. Bu düşünceden dolayı sayılara olan inançlar ortaya çıkmıştır. Bu inanışlar doğa olaylarını anlatır yaşam sırlarını anlamayı kolaylaştırır. Sayıların taşıdığı bu özel anlamlar her milletin kültüründe görülmektedir. Her kültürde sayıların kutsal olduğu ve onların insanları etkilediği düşünülür. Bazı sayılar hayata başarı ve mutluluk getirirdi, bazıları şanssızlık getirebilirdi. Sayılara yüklenen bu anlamlar geçmişten günümüze gelenek olarak yaşamaya devam eder. Türklerin sayılara ilişkin inançlarının izleri masallarda, hikâyelerde, destanlarda, efsanelerde, atasözlerinde, deyimlerde vb. türlerde görülebilmektedir. Türk kültüründe taşıdığı anlamlara göre bazı sayılar "kutsal" olarak kabul edilmektedir. Kutsal sayılan mitolojik sayılar içinde "bir", "üç", "dört", "beş", "altı", "yedi", "dokuz" ve "kırk" en yaygın olanlarındandır. Bu makalede Türk kültüründeki ve edebiyatındaki "yedi" sayısının taşıdığı özel anlamlardan bahsedilmektedir.

Anahtar Kelimeler: Yedi, sayılar, Türk mitolojisi, halk kültürü, halk edebiyatı.

\section{NUMBER SEVEN İN TURKISH FOLK CULTURE AND LİTERATURE}

Abstract: In mythological times people tried to know themselves and to get familiar with natural phenomena. They considered themselves as a part of this nature. These thoughts arose beliefs in numbers. These beliefs would tell about natural events and help to understand the secrets of life. The special meanings of the numbers are seen in the culture of every nation. In every culture, numbers were considered to be a sacred property and they had some effect on people's lives. Some numbers would bring success and happiness to life, some could bring bad luck. The special meanings attributed to numbers are an element in the lives of Turkic peoples that continue to live as a tradition in the present. These beliefs in numbers can be seen in fairy tales, stories, epics, legends, proverbs, idioms, etc., which are the products of folk culture that have continued since ancient times. Some numbers are accepted as "sacred" according to their meanings in Turkic cultures. Among the mythological numbers considered as sacred, "three", "four", "five", "seven", "nine" and "forty" are the most common. In this article, there will be mentioned the special meanings of the number "seven" in the culture and literature of the Turkic World.

Keywords: Seven, numbers, Turkic mythology, folk culture, folk literature.

* Bartın Üniversitesi, Lisansüstü Eğitim Enstitüsü, TDE Doktora Öğrencisi, ORCID ID: 0000000317204598 


\section{Giriş}

İnsanoğlunun hayatında sayıların önemli bir rolü vardır. Hepimizin çevresinde saat 00.00 olduğu an dilek tutan insanlar mevcuttur. Örneğin; bu inanışa sahip olan insanlardan bazıları mutluluk ve şans getirmesi dileği ile 20.02.2020 günü piyango bileti satın almışlar, nikah kıymışlardır. Yine 07.07.07 gününe mutluluk günü diyerek, tam o gün evlenirse bütün hayatı boyunca mutlu yaşayabileceğine inanan insanlar için pek çok ülkede evlendirme daireleri ve kilise, cami gibi ibadet yerleri 24 saat hizmet vermiştir.

Sayılara olan bu inanışlar son zamanlarda ortaya çıkmış değildir. Eski zamanlardan beri inanıldığına göre her sayının gizli anlamları vardır: bazı sayılar insanlara bol kazanç ve şans getirmekteydi, bazıları ise başarısızlığa neden olabilmekteydi. Birçok kültürde, ayrıca Babil, Hint, Mısır uygarlıklarında sayılar her şeyin başlangıcı olarak görülmektedir. Matematiğe yaptı̆̆ı katkılarla "Sayıların Babası" olarak anılan Pisagor "Dünya sayıların gücü sayesinde yaratıldı." demektedir (Melenko, 2012: 70-77). Pisagor sayıları sadece matematiksel olarak araștırmamış, her sayının dünyadaki yerini ve anlamını da çözmeye çalışmıştır.

Taşıdığı anlamlara göre bazı sayılar "kutsal” olarak kabul edilmektedir. Bu sayılara özel anlamlar yüklendiği ve bu sayıların kutlu sayıldıkları halk ürünlerinin içinde hikâye, destan, masal, atasözü, efsane ve batıl inançlarda görülmektedir (Bozkurt ve Bozkurt, 2012: 718).

$\mathrm{Bu}$ makalede yedi sayısının Türk dünyası edebiyatında ve halk kültüründe nasıl kullanıldığı ve taşıdığı anlamlar üzerinde durulmaktadır.

\section{Yedi Sayısının Türk Halk Kültürüne Yansıması}

Schimmel (2000: 140) "Sayıların Gizemi" adlı çalışmasında yedi sayısını "bilgeliğin sütunları" olarak adlandırır ve "4 elementi kuşatan ve duygusal güçlere karşılık gelen maddî dörtlemeyle (hava=zekâ, ateş= istenç, su= duygular, toprak=ahlâk) birlikte yaratıcı ilkelerin üçlüğünü (aktif zekâ, pasif bilinçaltı ve iş birliğinin düzenleyici gücü) içerir" demektedir.

Yedi sayısı çoğu kültürde ve inanışta yaygın olarak kullanılan bir rakamdır. Mısır uygarlığında bu sayı sonsuz bir hayatın belirtisi olarak düşünülmektedir. Sümerler zamanında yapılan bir ibadethanenin yedi kapılı olduğu ve inşaat işi bittikten sonra bu ibadethanede yedi inek, yedi koyun kurban kesildiği bilinmektedir.

İslam dünyasında da yedi sayısının özel anlamı vardır. Dini yazılara göre cennetin yedi kapısı, cehennemin ise yedi basamaklı merdiveni mevcuttur. Hacca giden kişiler ibadet yaparken Kabe'nin etrafında yedi kez dolaşırlar. 
Eski Ahit'te Tanrı dünyayı altı günde yaratmıștır, yedinci gün istirahate çekilmiştir. Kuran-1 Kerim'in Kaf suresinin 38. ayetinde “Andolsun biz, gökleri, yeri ve ikisi arasında bulunanları altı günde yarattık. Bize hiçbir yorgunluk çökmedi." denmektedir (Yücel, 2011: 28). Türk mitik metinlerinden Altay Yaratılış destanlarında bu olay “Tanrı altı günde dünyayı yarattı, yedinci gün dinlendi diye anlatılmaktadır." (Ögel, 2010: 462). Bununla birlikte Kuran-i Kerim VII yüzyılda yere düștü delinen tahminler de var (Düsipbayeva, 2001: 97). Kur'an-ı kerim yedi harf üzerine inmiştir. Mekke ve Medine arasında yedi kale vardır. Kur'an-ı Kerim'de Yusuf Peygamber kıssasındaki rüyaya göre yedi besili ineği, yedi zayıf inek yer yorumunda yedi yıl kıtlık olur. Cuma namazının yedi farzı vardır (Yardımcı, 2009: 641-642).

Yedi sayısı Türk dünyasında kutsal sayılmaktadır. Altay Türklerinde ayın tutulmasına "yedi başlı dev" denir. Kırgız ve Kazak Türklerinde gökyüzünde bulunan "büyük ayı" yıldızlarına "yedi bekçi" derler ve eskiden yolunu kaybetmiş insanlar bu "yedi bekçi”ye bakarak yolunu bulmuşlar. "Büyük ayı" burcuna diğer Türk boyları "yedi kör", "yedi eşek", "yedigen”, "yedi at", "yedi kardeşler”, yedi vahşi köpek”, “yedi han”, “yedi hırsız", “yedi kurt”, “yedi aygır” gibi çeşitli isimler koymuşlardır. (Yüksel, 1980: 18).

Türklerde sayıların anlamları iki farklı amaçla ortaya çıkmıştır: Birincisi dünyayı tanımak, bu insanların tabiat olaylarına karşı duyduğu korkudan dolayı oluşmuştu. İkincisi ise mitolojik düşünceden, yani insanların kendilerini tabiatın bir parçası olarak kabul etmesinden dolayı ortaya çıkmıştır (Rıskulbek, Yermekova, ve Yeskermesova, 2020: 142-157).

Orta Asya kültüründeki sayıların gücüne olan inanış onların İslam dinini kabul etmesinden önce oluşmuştur. Eskiden Şamanizm düşüncesine sahip olan Türklerin Güneş Tanrısına, Ateş Tanrısına, Su Tanrısına inandığı bilinmektedir. Yuvarlak şekilde pişirilip dağıtılan yedi ekmek Kazak Türklerinin kültüründe günümüzde de yaşamaya devam eden bir gelenektir. Bu ekmeklerin yuvarlak olması ve yedi tane olması yedi gezegenin olduğunu anlatır. Böylece yedi ekmek pişirerek Kazak Türklerinin Güneş Tanrısına inandığı söylenebilir (Riskulbek, Yermekova, ve Yeskermesova, 2020: 142-157).

Türk inanışlarında güneşin batımı ile doğumu, ayın şekli kontrol edilip, buna göre hava durumu, mevsimler belirlenmiştir. Bu hareketten dolayı yedi olay ortaya çıkmıştır. Birinci olay gün dönümü: Yaz mevsimindeki gün dönümü 21 Haziran'da, kış mevsiminde 22 Ocak'tadır. İkinci olay Kasım dönümüdür. Bu zamanda kuşlar ılık yerlere uçup giderler, ilk kar yağar. Üçüncü olay Ülker'in batımıdır. Haziran ayında Ülker yıldızı gökyüzünden kaybolur. Kazak Türklerinde “Ülker düşmeyince yer ısınmaz.” atasözü buna göre ortaya çıkmış olabilir (Rıskulbek, 
Yermekova, ve Yeskermesova, 2020: 142-157). Dördüncü olay, buzun tutmasıdır. Suyun üzerine buz oluşmasından itibaren soğuk gelir. Beşinci olay, geyiklerin tutulmasıdır. Bu olay Ülker yıldızının kış mevsimindeki kayboluşuna denk gelir. Kasım ayının soğuğu başlar. Altıncı olay, kış dönemidir. Kış aylarının girmesi diye anlatılır. Yedinci olay, Ay’ın ve Ülker'in bir arada görünmesi olayıdır.

Yedi hazine, yedi gün, yedi yok, yedi sağlık, yedi yut, yedi aşık, yedi ata düşünceleri, vefat etmiş olan kişiler için her yedi gün yedi ekmek pişirerek Kuran bağışlamak gibi gelenekler yedi sayısının Kazak kültüründeki görünümlerindendir. Bu unsurların taşıdığı manalar şu şekilde açıklanabilir:

Yedi kat gök: Ay, Merkür, Venüs, Güneş, Mars, Jüpiter, Satürn gezegenleri “yedi kat gök” anlamını verir. Türklerdeki "ydi kat gök" düşüncesi cennetin yedi kattan oluştuğunu ve yedinci katın en değerli olduğunu anlatır. Türklerin eski inanışlarına göre gök yüzünde yedi gezegen vardır ve yukarıda bahsettiğimiz "yedi kat gök" düşüncesi de bundan dolayı ortaya çıkmıştır (Uali, 1988:103).

Yedi hazine: Güzel kadın, akıl ve bilgi, hızlı koşan at, kartal, tüfek, keskin kılıç, tazı köpektir. Bu hazineler erkeklerle ilgili olup, bunların hepsine sahip olan erkeğin en zengin olacağına inanılır. Buradaki hızlı koşan at erkeğin kanadı, kartal - gücü ve kuvveti, tazı - onuru, tüfek -karakteri, güzel kadın - erkeğin yâri, kılıcı - güveni olarak sayılır.

Yedi gün: Haftanın yedi günüdür. Bir hafta anlamında Kazak Türkleri “yedi” derler. Örneğin, bir hafta sonra demek yerine bir yedi sonra derler.

Yedi yok: Gökte dayanak yok, yerde ölçü yok, kaplumbağada dalak yok, Allah'ın kardeşi yok, kuşun sütü yok, atın safrası yok.

Yedi yut: Kuraklık, hayvanların ölümü, yangın, veba, savaş, sel, depremdir. Kazak Türkleri bu olayları yut diye adlandırır. Halk arasında "Yut yedi kardeș." atasözü de kullanılmaktadır.

Yedi âşık: Leyla ile Mecnun, Yusuf ile Züleyha, Ferhad ve Şirin, Bahram ve Kulande, Seyfülmalik-Badiğul-Jamal, Bozjiğit ve Ayula, Ziyada ve Horlu'dur. Bunlar Doğu Edebiyatından kahramanlardır.

Yedi ata: Dede, baba, çocuk, torun, şöbere (torunun çocuğu), şöpşek (şöberenin çocuğu), nemenedir (şöpşeğin çocuğu). Kazak Türklerinin "Yedi atasını bilmeyen akılsızdır" diyen atasözü vardır. Bu yüzden çocuklar yeni konuşmaya başladıklarında büyükler ilk önce onlara yedi atasını öğretmeye başlarlar. "Yedi ata" anlamının altında büyük bir felsefe vardır. Şimdiki zamanda da 
yedi atayı geçmeyince gençlerin evlenmesi yasaktır. Bu çocukların sağlıklı olmasını ve kanın saflığını sağlar. Yedi atayı geçmeden evlenenlerin ise çocuklarında her türlü psikolojik ya da genetik hastalıklar olma ihtimali olduğu söylenmektedir. Bu inanış Türkmenlerin kültüründe de görünmektedir. Türkmenlerde her bir insanın bilmesi gereken yedi önemli şey vardır ki bunlar; oğul, torun, çovluk, yuvluk, govluk, yatlık, atlık'tır. Bunun yanı sıra ünlü şair Magtımgulı'nın ifade ettiği gibi, her bir insanın yedi dedesi vardır. Bunlar kendi dedesi, Kayın dedesi, Adam atası, Azan dedesi, Oğuzhan dedesi, Nuh dedesi, İlim dedesi'dir (Kılıç, 2016: 751).

Yedi sağlık: İnsanın sağlığı için en gerekli olan organları, iki gözü, iki kulağı, burnunun iki deliği ve ağızdır (Iskakov, 1965: 167).

Kazan Tatarlarının inanışına göre huzursuz bir çocuk için geceleyin bahçe kapısına lapa pişirilip konur. Buna "Gece Lapası" denir ve bu lapanın yanına yedi kaşık koyulur. Bu yedi kaşığın çocuğu yedi büyüye karşı koruduğuna inanılır. Çocuğun doğumunun yedinci günü kurban kesilir. Cenaze törenlerinde ölüyü yıkayana ölünün yedinci günü sadaka verilir. Ölünün yedisinde de kuymak pişirilir (Çetin, 2009).

Kazak Türklerinde çocuk doğduktan yedi gün sonra beşiğe yatırılır, bunun nedeni yedi günde çocuğun göbek kordonunun düşmesidir. Müslümanlarda erkek çocuk yedi yaşına gelince sünnet ritüeli yapılır. Kazak kültüründe çocuğu olmayan annelerin yedi evden un alarak "Bibi Süişembi Ana”ya yemek verme geleneği var (Düsipbayeva, 2001: 97). Anadolu'da da durumu iyi olan aileler çocuk doğduktan yedi gün sonra mevlit okuturlar (Erol Çalışkan, 2017: 461).

Nahçivan halk inanışına göre, Nahçıvcan'daki en mukaddes yerlerin biri olan "Asafkef"'i yedi defa ziyaret eden insan Kerbelâ'yı ziyaret etmiş sayılır (Kadirzade, 1998: 213). Azerilerin “Albastı'nın çarptığı kadın, kısır olmamak için taşkın ırmağı yedi kez geçmeli” inanışları da var (Beydili, 2005: 489).

Yedi sayısı Türklerin deyimlerinde de yer almaktadır. Yedi canlı, yedi düvel, yedi denizin attığı, yedi iklim dört bucak, yedi kat el, yedi kubbeli hamam kurmak, yedi mahalle, yedisinden yetmişine, yediye gitmek deyimleri de bu sayının Türklerde önemli bir rolü olduğunu göstermektedir. Bu deyimlerin anlamları şu şekildedir:

Yedi canll: Pek çok ölüm tehlikesi geçirip sağ kurtulan insan ya da hayvan.

Yedi düvel: 1. Bütün devletler. 2. Herkes, bütün dünya.

Yedi denizin attığı: Hiçbir çevrede kendisine yer verilmeyen, herkesin kendisinden tiksindiği kişi. 
Yedi iklim dört bucak: Hemen her yer, bütün dünya.

Yedi kat el: Çok yabancı.

Yedi kubbeli hamam kurmak: Büyük hayaller peşinde koşmak.

Yedi mahalle: Herkes, bütün çevre.

Yedisinden yetmişine: En büyüğünden en küçüğüne, eli ayağı tutan herkes.

Yediye gitmek: Gelinin koca evine gittikten yedi gün sonra, baba evini ziyaret etmesi.

Sıralanan örnekler Türklerde yedi sayısının kutsallığını gözler önüne sermektedir. $\mathrm{Bu}$ inanış Türk Halk Edebiyatında kahramanların demirden yapılan yedi kat giysi giymelerinden, yedi kat yerin altına düşüp, yedi katlı duvarı yıkmasından, yedi deryayı geçmesinden görünür.

\section{Türk Halk Edebiyatındaki Yedi Sayısı}

Bazı sayıların tekrarlandığı ve sayı simgeciliği Türklerin ilk yazılı kaynakları sayılan Orhun Abideleri'nde görülmektedir. İlteriş Kağan “Babam Hakan on yedi adamla baş kaldırmış. İlteriş baş kaldırıyor diye haber alıp şehirdekiler dağa çıkmış, dağdakiler şehre inmiş, derlenip toplanıp yetmiş kişi olmuşlar... sonunda hepsi yedi yüz kişi olmuşlar" demektedir. (Tekin, 2014: 27). Bu yazılarda tekrarlanan 17, 70 ve 700 aynı zamanda mitolojik katları ifade etmektedir. Türkler yediye bir on ilave ederek sonra da yediyi on ile çarpmak suretiyle kökü yedi rakamından gelen bu katları elde ederler (Kumru, 2017: 25).

"Alpamış" destanında Alpamış'ın yedi yaşına gelince ata binmesi, Karajan'la savaştığında yedi pirine dua etmesi, Karajan'ın yenildikten sonra yedi adım yürüyüp yere düşmesi, Tayşa Han'ın şehrine kadar yedi gün, yedi gece yolda yürümesi, Karajan'ın yedi günlük uykuya dalması, Alpamış'ın yedi yıl zindanda kalması gibi motifler bulunmaktadır (Alpamış Batır, 1979). Alpamış'ın yedi yıl zindanda kalışı Hz. Yusuf'un yedi yıl zindanda kalışına telmihtir. Ayrıca destanda Alpamış zindanda mahsur iken kendisi ile Hz. Yusuf arasında bir bağ kurmuştur. Destandaki sayıların genellikle dinî semboller içerdiği buradan hareketle söylenebilir (Erol, 2019: 190).

Yedi pire sığınmak motifi "Kobılandı Batır" destanında da vardır. Seksen yaşına gelen Toktarbay çocuk dileyip yedi pire dua eder. Duası kabul olur bir oğlan, bir kız çocuğu dünyaya gelir. Oğlanın ismini de Kobılandı koyar. Kobılandı büyüyüp savaşa gitmeden önce eşi Kurtka rüyasında Kobılandı'nın yedi cennette gezdiğini görür. Destanda Kızılbaşların yedi katlı şehirleri vardır. Kobılandı Kızılbaşlarla yedi gün savaşıp yedinci gün kazanır (Kobılandı Batır, 2016). 
"Edige" destanında da Edige'nin yedi gün Cebrail meleğe sığınması motifi vardır (Babalar Sözü, 2006: 9-44).

"Edige" destanında, Edige yedi başlı, bir kuyruklu yılana rastlar. Yılanının yedi başı yuvaya sığmaz, yedisi yedi tarafa yayılır. Edige ve arkadaşları da yılanı öldürürler. Giderken yedi kuyruklu, bir başlı yılana rastlarlar. Öldürmeye karar verirler, bir başın ardından yedi kuyruğu da mağaraya gider, öldüremezler. Edige, bu durumdan ibret almak gerektiğini, yedi başlı bir kuyruklu yılanı öldürdükleri hâlde bir bașı, yedi kuyruğu olanı öldüremediklerini söyler. Bunun üzerine Edige’yi baş seçerler (Bekir, 1999: 62). Bu destanda; Edige, oğlu Nuradin'e “Bana yedi sultanın başını mı getirdin yoksa?" diyerek soru da sorar (Bekir, 1999: 71).

"Çora Batır" destanında, Çora Kazan'ı almak için yedi gün yedi gece mücadele eder (Bekir, 1999: 88). “Köroğlu” destanında, Köroğlu Bezirgan’a, “yedi yıldan beri Çamlıbel'de durduğunu, yedi kat nalı birden burduğunu" anlatır (Bekir, 1999: 102).

“Kozukürpeç - Bayan Sulu” hikâyesinde Kozu, yedi gün, yedi gece uyur (Bekir, 1999: 115).

"Tahir ile Zöhre" hikâyesinde, "Tahir" "Taz oğlan"a yedi yıl onun yerinde kalırsa ve kendisini Tahir olarak tanıtırsa padişahın kızını vereceklerinisöyler (Bekir, 1999: 110).

Kırım Tatarlarının hikâyelerinde; "yedi başlı bir kuyruklu yılan”, "yedi kuyruklu bir başlı yılan”, “yedi sultanın başını getirme”, “yedi gün yedi gece mücadele etme”, “yedi yıl mühlet”, "yedi yıl içinde yedi tulum altını başlık parası isteme", "başlık parası kazanmak için yedi yıl başka bir şehirde çalışma", "hediye getirilen elbiseleri yedi gün boyunca giyinme", "yedi yıl bir yerde yaşama", "yedi kat nalı birden burma", "başkasının yerine geçtikten yedi yıl sonra padişahın kızıyla evlenme", “yedi gün yedi gece uyuma”, vd. gibi motifler görülmektedir (Durbilmez, 2007: 184).

“Dede Korkut" Hikâyeleri'nde Bamsı Beyrek'in yedi kız kardeşi vardır. Beyrek, sonunda bu sadık kız kardeşlerini kırk yiğidinden yedi tanesiyle evlendirir. Destanda yedi sayısıyla ilgili "Heman-dem kümbed yarıldı, yedi yerden kapu açıldı” (Özçelik, 2016: 465), "Beyrek dahı yedi kız karındaşını yedi yigide verdi" (Özçelik, 2016: 249), "Yedi gün yedi gece toy düğün edüp yeme içme oldı" (Özçelik, 2016: 587), "Yedi katla vardum o kal'ayı alamadum gerü döndüm” (Özçelik, 2016: 421), “... kara blyığın ensesinde yedi yerde dügen Kazan Begün kartaşı Kara Göne çapar yetdi” (Özçelik, 2016: 125) gibi kullanımlar vardır.

“Dede Korkut”ta Dirse Han'ın eşi çocuğunun yarasını tedavi etmek için Kıdır Baba'nın dediklerini dinleyip, yedi türlü bitkiden ilaç yapar. Oğuz bahadırı Karagöme uzun bıyıklarını 
yedi yerden bağlar. Salur Kazan yedi günlük yemek alıp yola çıkar, yerine dönmek için yedi gün, yedi gece yol yürür. Salar Kazan'ın önüne çıkan ejderha yedi başlı olur, kâfir kız da yedi yaşında olur (Rıskulbek, Yermekova, ve Yeskermesova, 2020: 142-157).

Yedi sayısı "Manas" destanında da yer almaktadır. Er Kıyazla Külçora yedi gün savaşır. Seyrek Külçora'yı yedi gün tedavi eder, yedi gün sonra Külçora eski sağlığına kavuşur. Esen Han'a Konurbay'ı şikâyet eden Almambet yedi gün cevap bekler. Çevreye yiyecek aramaya çıkan Kanıkey kaynanası Çıyırdı Hatun'a “Yedi gün gelmezsem ölümümü bekle.” der. Manas'ın babası Cakıp Han, Kanıkey'in mihrini yedi gün içinde Demir Han'a teslim edeceğini bildirir (Yücel, 2011: 59).

Manas destanında Kreşti şehrinde Almambet'in şerefine kurban edilmek için yedi kişinin getirilmesi; Köketey Han'ın, yetmiş yiğidiyle ava çıktığında bir erkek çocuğu bulması ve çocuğun bakımı için yedi kadın tayin etmesi; Er Töştük'ün yerin altında yedi yıl kalması; Burulça'nın , Almambet'e "Ben seni yedi sene beklerim." demesi; Manas dünyaya geldiğinde Köketay'ın aş törenine gelen Orakkır'ın beraberindeki askerlerin yedi tane tuğ taşımaları olaylarında yedi sayısı tekrarlanmaktadır (Radlof, 1976: 202-205).

Kız Jibek destanında yedi deryadan söz edilir. Yedi derya toplanıp Kara Denize dökülür. Jibek'in sevgilisi olan Tolegen yedi ayda geri döneceğini söyler. Tolegen'in babasının yedi yüz develik dünyası olduğundan bahsedilir. Koren Han'ın yedi atadan beri han olduğu söylenir (Kız Jibek, 2003).

Türk dünyasının masallarında "yedi başlı ejderha", "yedi gün yedi gece düğün", "saçları yedinci kattan yere ulaşan kız", "yedi günlük uyku”, "yedi yıllık vergiden kıymetli telek", "yedinci oda", “yedi kardeş", “yedi yol ağzı", "yedi kat duvar”, “yedi yıl mühlet” gibi yediyle ilgili motifler görünmektedir (Durbilmez, 2007: 184).

\section{Sonuç}

Türklerde "yedi" sayısının taşıdığı anlamlar ve kullanım alanları aşağıdaki gibi sıralanabilir:

- Kozmogonik eylemlerden oluşan dünya sırlarını anlatmak: yedi kat gök, yedi bekçi, yedi gün, yedi yut, yedi ekmek, yedi yok, yedi olay.

- Nesiller arasında oluşan bağı anlatmak: yedi ata.

- Belli bir olayın anlamını güçlendirmek, anlamını daha etkili hale getirmek: yedi gün yedi gece yolda yürümek, yedi gün yedi gece uyumak, yedi yıl zindanda kalmak. 
- Dini motifleri anlatmak: yedi pire sığınmak, yedi yaşa gelince ata binmek (yedi yaş İslam'da sünnet yaşı olarak, ilk olgunluk yaşı olarak kabul edilir).

- Belli bir sayının anlamını güçlendirmek için sayıya bir on ekleyip anlatmak: on yedi, yetmiş, yedi yüz.

- İnsan hayatının bütünlügünü anlatmak: yedi hazine, yedi sağllk.

Bu çalışmada incelenen Türk kültüründeki ve edebiyatındaki "yedi” sayısının gizemleri Türk dünyasına İslam gelmeden önce ortaya çıkmış ve dinin gelmesi ile anlamı daha da derinleşmiştir. Edebiyatta ise yedi sayısı bazen dini motifleri anlatmak için, bazen de olayın anlamını güçlendirmek, olayı daha etkili halde anlatmak için kullanılmıştır.

Sayılar üzerine her ne kadar çok çalışma yapılsa da hala araştırılıp bitmeyen sihirli, mistik bir tılsım dünya. İleride yapılacak çalışmalarda sayıların taşıdığı anlamları daha derin incelenmesi gerekmektedir.

\section{KAYNAKÇA}

Alpısbayeva, K., Ayesbayeva P. (ed.) (2006). Babalar Sözü. 39. Cilt. Astana: Foliant.

Bekir, C. (1999), Kırım Halk Edebiyatı. Türkiye Dışındaki Türk Edebiyatları Ansiklopedisi 13: Kırım Türk-Tatar Edebiyatı. https://ekitap.ktb.gov.tr/TR-78531/kirim-halk-edebiyati.html adresinden erişildi.

Beydili, C. (2005). Türk Mitolojisi Ansiklopedik Sözlük. Ankara: Yurt Kitap yayınları.

Bozkurt, K. ve Bozkurt, H. (2012). Sayıların Gizemli Dünyası: Kültür ve Edebiyatta Sayı Sembolizmi. Batman Üniversitesi Yaşam Bilimleri Dergisi, 1, 717-728.

Çetin, Z. Çulpan. (2009). Tatar Türklerinin Gelenekleri ve Görenekleri. Ankara: Karadeniz Dergisi yayınları.

Durbilmez, B. (2007). Kırım Türk Halk Anlatılarında Sayı Simgeciliği. Milli Folklor, 76, 177-190.

Düsipbayeva, K. (2001). Kazak Eskiliklerinin Sayılar Sistemindeki Görünüşü. Almatı.

Erol Çalışkan, Ş. S. (2019). Alpamış Destanında Sayıların Anlamları ve Değerlendirilmesi Üzerine Bir İnceleme. RumeliDE Dil ve Edebiyat Araştırmaları Dergisi, 14, 183-197.

Erol Çalışkan, Ş.S. (2017). Anadolu Kültüründe Doğum ve Cinsiyet Belirleme Ritüelleri. $I$. Uluslararası Dil ve Edebiyatta Modernleşme ve Gelenek Sempozyumu Bildiri Kitabı, Karabük: Karabük Üniversitesi Yayınları, 457-469.

Iskakov, M. (1965). İlim ve Kör İnanışlar. Almatı.

Kadirzade, K. (1998). Nahçıvan'da Mukaddesler, Eren ve Evliyalarla İlgili Kutsal Yerler. I. Uluslararası Türk Dünyası Eren ve Evliyalar Kongresi Bildirileri. Ankara: ERVAK yayınları. 
Kumru, C. (2017). Türk Mitolojisi Penceresinden Orhun Abidelerine Dair Değerlendirmeler. Ulakbilge, 6/ 20, 7-26.

Kılıç, S. (2016). Eski Türk Topluluklarında Sayı Sembolizmi ve Türkmen Takılarına Yansiması. International Periodical for the Languages, Literature and History of Turkish or Turkic Volume, 11/2, 733-754.

Kız Jibek destanı (2003). Almatı: Mektep.

Melenko, S. (2012). Философские и государственно-правовые взгляды Пифагора Самосского. Вопросы современной юриспруденции: сб. ст. по матер. Х междунар. науч.практ. конф. Новосибирск: СибАК.

Ögel, B. (2010). Türk Mitolojisi. I. Cilt. 5.bs., Ankara.

Özçelik, S. (2016). Dede Korkut -Dresden Nüshası- Giriş, Notlar (1. Cilt), Ankara: Türk Dil Kurumu Yayınları: 1166/1.

Radlof, W. (1976). Sibirya'dan (Seçmeler). Çev. Ahmet Temir, İstanbul: Milli Eğitim Basımevi, 1. Baskı.

Rıskulbek, D., Yermekova, T., Yeskermesova, G. (2020). Yedi Sayısının Tanımı. Dünya Yörük-Türkmen Araştırmaları Dergisi, 2, 142-157.

Şayahmet A. (ed.) (2016). Kobılandı Batır. Kostanay.

Seydimbekov, A. (ed) (1979). Alpamıs Batır. Almatı.

Schimmel, A. (2000). Sayıların Gizemi, 2. bs., İstanbul.

Tekin, T. (2014). Orhon Yazıtları. Ankara: Türk Dil Kurumu Yayınları.

Uali, N. (1988). Gizemli Yediler. Jalın Dergisi, 3, 103.

Yardımcı, M. (2009). Geleneksel Kültürümüzde ve Âşıkların Dilinde Sayılar. ÇÜ Türkoloji Araştırmaları, 636-647.

Yücel, U. (2011). Türk Halk Inanışlarında Sayılar. (Yayımlanmamış yüksek lisans tezi). Ankara Üniversitesi, Ankara.

Yüksel, H. Avni. (1980). Türk Folklorunda 7 Sayısı. Erciyes: Aylık Sanat ve Fikir Dergisi, 29, 18-22. 